had seven or eight fits; he had one when twenty-one, and another when twenty-two; another when twenty-three, and in October 1866, four. $\mathrm{He}$ ascribed the last series to injuries received in an explosion; but there is only' evidence that his leg was broken.

Since admission (1869), he has had several seizures, which are thus described. He feels to come over in a shake; he imitates it so as to suggest general tremor or shivering, I could not tell which, not convulsion. Then he sees things in confusion, and "has a smell". This smell he cannot describe "beyond saying that it is "faint", "curious", etc. At the same time, he makes a smacking noise with his lips, and, unless "it" (the fit) comes on very strong, he can talk. Besides the above things, he has in every attack, for the previous two or three years, a feeling of being "somewhere else". He said that, one day, having a fit at breakfast, he fancied he was reading. He also described with this a negative state, a fading away and getting into a mist. (I ascertained that this was a metaphorical expression as to his mental condition; he did not then mean "mistiness of sight".) He has many attacks which pass off. The above is only what is described by himself. When they "progress", as his friends say, he makes for the door, and walks, his father says, at a "terrific pace". My inference is that this so-called progress of the fit consists of actions after a fit. Sometimes he is very violent, raves, kicks, and tears, and they have to call in people to control him. In this state, he has broken chairs, tables, basins, etc. $\mathrm{He}$ remembers nothing of these actions. In or after one of his slighter attacks, he was supposed by the foreman to be intoxicated, and on another occasion was accused of stealing, because in his insensible state he took a fellow-workman's jacket.

In, or as I suppose just after, some of these seizures, the patient talks nonsense, as the friends report. On talking after seizures of epilepsy proper, I have very few precise facts: the talk may be in some cases part of the carrying out of a sort of dream, and thus not nonsense in regard to the patient's then mental state; sometimes it may be partly aphasic. After some epileptiform seizures, there is decided temporary aphasia.

There is one other matter. I have been much struck, in looking over my case-books, by finding that a good many cases in which there are "dreamy states" are those in which there is also some "warning", roughly referable to. the digestive system (smell, metallic taste, epigastric sensation), or else some phenomenon in or after the paroxysm, which seems explicable on there being a crude sensation of taste (or excitation of nervous arrangements concerned in taste), as movements of mastication and spitting out. I commit myself to no conclusions on the matter beyond the provisional conclusions called hypotheses. There are exceptions; the "dreamy state" occurs sometimes without other warning that I can hear of. The scientific statement would be that the "dreamy state" occurs with some sensation (declared or inferred) which is especially subjective, as opposed to objective. But here is a difficulty. All, or at least many, sensations are either objective or subjective ac cording as they are then serving; taste serves subjectively in digestion or in anticipation of digestion (agreeable or disagreeable), and objectively when used to recognise some quality in a substance; that it tastes like or unlike some other substance. Smell serves not only subjectively, but particular scents revive most voluminous past scenes. In no case can we suppose the "dreamy state" to be a symptom of the same order as the crude sensation which may go along with it; for the crude sensation attends the epileptic discharge; the dreamy state is infinitely too elaborate to have such causation. It is supposed to be owing to "loss of control", and possibly may depend on rise in activity of the opposite cerebral hemisphere.

\section{A LARGE CHILD.}

ON Christmas-day, 1852, I attended a patient in her confinement, and the newly born child weighed twenty-one pounds. I had attended the same patient in some previous confinements, and all the children were exceptionally large when born; but the one born in 1852 appeared to be considerably larger than the others, and I requested that it might be weighed. Not long after its birth, the child was taken to the house of a neighbouring farmer, and the farmer's wife, who was pregnant at the time, was so struck with the size of the child that she burst out crying when she thought of what the mother must have gone through in giving birth to such a child. On this point, I would only say that the labour was not by any means a very severe one. Several of the members of this family and all the brothers are very tall and very large. The weight of the largest new-born children which I find recorded is eighteen to twenty pounds. I have never heard or read of any case beyond twenty pounds, and that in only two or three cases.

C. W. ChCBB, M.R.C.S., Torpoint, Devonport.

\section{AN EXAMINATION}

\author{
INTO
}

\section{CERTAIN RECENTLY REPORTED PHENOMENA IN CONNEXION WITH HYSTERO-EPILEPSY AND CEREBRAL ANÆSTHESIA.}

BY GEORGE SIGERSON, M.D., Ch.M., F.L.S.

Member of the Royal Irish Academy, of the Scientific Society of Brussels, and of the Clinical and Anthropological Societies of Paris.

THE discoveries which have been recorded in Paris in connection with hystero-epilepsy and cerebral anæsthesia are undoubtedly of high interest, whether we consider them from a pathological or a physiological point of view. It is, therefore, desirable to ascertain if they be established upon a firm basis or not. Certain difficulties have been suggested, which appear to stand in the way of their acceptance by some minds; but this is neither surprising nor to be deplored. Newcomers in science must run the gauntlet of criticism, and demonstrate that they have sufficient vitality to withstand the severest test. To me it appears that the chief cause of the objections alleged lies in the fact that the results of the research are better known and more prominent than the methods of investigation, whilst these results are of themselves so remarkable as to overshadow the minute details of the process of inquiry followed. As it has been my good fortune to be well acquainted with the hospital which has been the principal scene of these investigations, and to have assisted at some researches there, I feel myself bound, alike in the interest of scientific progress and out of respect for those who assert and those who deny, to state my reasons for believing that certain important facts have been securely established.

It is right to remember, in the first place, that we have here, not simply the assertions of an investigator, but the labours of a commission appointed by an eminent society to examine and test his statements. It is little to say that the accounts given by Dr. Burq of the advantages derivable from his metallic treatment of disease did not fall upon minds unduly prepossessed in his favour. His operations, begun nearly thirty years ago, have been generally slighted; and, in one standard French work, they were denounced as "a resurrection of ancient cabalistic and astrological practices addressed to the imagination of patients". However, it is only fair to state that he made no mystery of his method, but courted inquiry; and one or two physicians who had sufficient curiosity to make the experiment confessed that, though his doctrine was incredible, his practice had some facts to show. Such was the state of medical opinion in Paris when, at his request, the Socićté de Biologie, two years ago, nominated a commission of inquiry, composed of three distinguished physicians: Dr. Dumontpallier, Dr. Luys, and Professor Charcot. The latter acted as president, and those who are conversant with his works, who know how rigorous has been his method of research, and how great his experience, must acknowledge that he was specially qualified for the position. When we are told of the precautions needful in cases of hysteria, it should not be forgotten that he is the great modern authority on this neurosis, and that those who need to be warned against the devices of the diseased will find their best safeguard in the perusal of his lectures. Besides, the proceedings of the commission had many distinguished witnesses, of whom it is sufficient to name Claude Bernard; and assuredly, if that great master of experimental research had suspected the investigation of inefficiency, he would have refrained from declaring that the results proved that "we are not yet very strong in the physiology of the nervous system". The verification of the facts educed by eminent physicians and physiologists from other countries must of itself suffice to distinguish them, broadly and deeply, from the effects produced by Mesmer, the causes of which were readily discerned by commissioners of inferior note and witnesses of less experience.

In approaching the study of new phenomena, we must put aside for a time our most cherished hypotheses, in order to act the part of impartial jurors, whose first duty it is to ascertain whether or not the facts be correctly stated, and whose privilege it then becomes to test the explanations offered, and to suggest others. At the very beginning of an examination into a debated question, it is surely wise to remember that both parties to the debate may be right in principle, and that their contest may resemble that of the knights concerning the shield. It has been suggested by an eminent authority, Dr. Carpenter, whose 
opinion must receive the respect which his exceptional intellect and great services command, that expectant attention may account for the production of the phenomena in question. Most assuredly, this scientific doctrine has served, in his hands, to strike down alike ignorant credulity and ignorant scepticism, and to firmly establish the potency of psychical causes over the production of physical phenomena. But none, I am sure, will be more ready than he to acknowledge that this doctrine has its limits; and it is my conviction that, had all the details of the investigation been before him, he would have excluded these results from its boundary.

An important argument is suggested when we ask, "Does the production of certain phenomena by the agency of expectant attention render their production by any other agency impossible?" If not, then the demonstration of the former may coexist with that of the latter. Now, it cannot be asserted that the operation of the first named agent is always, and in all cases, exclusive and contradictory of every other agency. Widely different causes may produce results apparently identical. Syncope, for instance, may be the consequence of a material injury or of a moral emotion; expectant attention or a physical lesion may operate in its production with equal effect. Hence it would be an error to suppose that proof of the production of certain phenomena by either agent is of itself sufficient to demonstrate that the other is impotent, and has not been operative in a given case.

With these preliminary observations, I shall now proceed to discuss in detail the principal points of the investigation, and to show that, in the conduct of the inquiry, the precautions taken were such as to exclude the interference of a psychical agent.

I. The Hysterical Tempirancnt.-Great stress has been laid upon the probability that deception will take place, either through conscious or uncoriscious action on the part of the patients, when we have to deal with persons afflicted with hysteria. All that has been said on this subject may be admitted, and even much more. "Hysterical breast" has been mistaken for cancer, and limbs have been amputated because of hysterical pains, whose nature was not diagnosed in time. But it is plain that, though a practitioner may occasionally fail to discern the existence of hysteria in the course of his practice, it is impossible that a physician should omit to suspect its manifestations in an hysterical ward. Those who have read Professor Charcot's lecture on Hysterical Ischuria* must remember both the emphasis of his admonitions and the fact that he did not hesitate to make use of the strait-waistcoat, in order to guard against the possible occurrence of error. It has been remarked by one writer, Dr. Donkin, that phenomena of morbid sensation and action produced in states of somnambulism and electro-biology, kindred phenomena to those produced at La Salpêtrière, are "covered by theories which do not require the causative agencies of magnets and metals". Now, it seems to me that we can bear to part with theories of psychical influence, if physical agency can be demonstrated; but, wanting this, it appears necessary to remark that, whilst induced lethargy and catalepsy are clinically studied at $\mathrm{La}$ Salpêtrière, the experimentation with metals and magnets is a thing apart and independent. Professor Charcot having found, to his surprise (and somewhat to his disappointment), that the attempt to cure a patient of hysterical contracture in the left arm by applying the magnet to the other only determined the transfer of the contracture to the right arm, has indeed succeeded in repeating this transfer in connection with induced contracture determined in a patient during the continuance of the state of somniation and catalepsy. The experiment has a peculiar interest, as it helps to elucidate the study of hysterical contracture; but this is a different question. The influence of the application of metals and magnets has been examined whilst the patients were in their normal condition. It is an instructive fact that the state of induced lethargy, suggestion, or subjection, during which the patient obeys directions given, is unfavourable to the production of phenomena by the application of metals. The patient becomes completely anæsthetic, and remains so. Again, it has been ascertained-and the fact is a remarkable one-that the experiments are most successful with patients in the normal state, when the hysteria is least pronounced. So far from the predominance of the hysterical condition at the approach of the paroxysmal period causing the applications to become more readily successful, it debars their success altogether for the time being.

Finally, the hysterical element can be eliminated. On the one hand, it has been found that a few rare hysterical patients are not affected by any of the many metals tried, and that most are affected by only one or two, proving utterly insensitive to the majority of them; whilst, on the other hand, it has been established that some patients who are not the victims of hysteria, but of well determined organic lesions, have ex-

* Charcot, Lectures on Diseases of the Nervous System, New Sydenham Society, perienced a decided improvement from the application of metals. This was not hoped for, and was contrary to the anticipations of Dr. Burq, when Professor Charcot resolved to test the influence of metals in the case of two non-hysterical patients, Rousille and Petit, in whom organic brain-lesion had produced profound hemianæsthesia, conjoined with post-hemiplegic hemichorea. Petit, aged 24, had been affected with hemianæsthesia for fifteen years. Rousille, aged 55 , had been stricken eleven years ago. No trace whatever of the hysterical diathesis was to be discovered in either patient; both were quiet; Rousille seemed almost apathetic. Now, contrary to all expectation, the application of metals succeeded here also in restoring special and general sensation ; the only difference was that his restoration, instead of being transient, as in hysterical cases generally, has remained constant for the past eighteen months. The reality of the change was attested, not only. by the commission, but likewise by Professor Vulpian, who took a particular interest in the subject, inasmuch as he had succeeded in dissipating a similar anæsthesia by means of the faradic currrent in 1875 . Thus it is demonstrated that hysteria is not an essential factor in the production of sensation-recovery in cases of hemianæsthesia.

2. The Hystcro-Epileptic Crisis and its Causes. - Referring to the influence of mental attention, Dr. Carpenter justly observes that its effects are most marked when there is a definite expectation of some particular result. He continues: "This came out very strongly in the inquiries of the commission appointed to report on the performances of Mesmer. The crisis, as it was then termed-we should now call it a hystero-epileptic convulsion-was found to come on when the patients believed themselves to be in magnetic communication with the baquet, whether they were or not." It may not be amiss to add that one of the commissioners, and he not the least distinguished, Laurent de Jissieu, drew up a separate report, in which, whilst condemning the belief in the influence of magnetised vases, etc., and whilst admitting that the imagination might produce similar symptoms, he nevertheless maintained that certain cases of convulsions and of nervous phenomena were entirely independent of the imagination. In order to prevent any misapprehension (though the precaution will make those who have been eye-witnesses smile), I think it useful to mention that the hysteroepileptic fit is not induced at $\mathrm{La}$ Salpêtrière by any suppositious " magnetic" means. The Salpêtrière School, in fact, prefers the physical to the psychical, and I am afraid some of its members work with considerable distrust on agencies that cannot be weighed, measured, or gauged.

The modes in which the hystero-epileptic fit is produced deserve notice here; for they illustrate what was laid down at the outset with respect to apparently identical phenomena being the results of widely dissimilar causes. Experience shows us that the first hystero-epileptic fit may have been produced in a patient by some violent emotion altogether apart from expectancy, such as a sudden fright. The convulsive paroxysm, once begun, goes through its evolution without being affected by any immaterial influence. More or less permanent disorders, however, may follow the fit, such as contracture and anæsthesia; and, after many years of endurance, these may suddenly, unexpectedly, and to the great surprise of the patient and her attendants, give way and vanish, owing to the occurrence of some powerful emotion, say the passion of anger. Thus was the recovery of the patient Etch-brought about.* Hence a strong emotion, without expectancy, may be operative in producing the hystero-epileptic fit; and, again, in delivering the patient from long-established contracture and anæsthesia, its consequences. As to the influence of emotion with cxpectancy, it may be held to produce the fits where they seem to be propagated, as it were, by contagion; and it may undoubtedly assist in effecting a similar deliverance. But, on the other hand, purely physical means may do the same work without the intervention of emotions, whether with or without expectancy. Thus, many years ago, my late revered master Dr. Duchenne (de Boulogne) found it possible, in certain cases, to remove hysterical anæsthesia and contracture by the application of faradic and galvanic electricity. It might be said that the cure was owing to the patient being in a state of expectant attention; but then, in cases of which the same thing could be asserted, the application failed. Next, the hysteroepileptic fit may be produced by physical agency, as, for example, by pressure on certain well known peripheral regions. $\dagger$ That anticipation

* Charcot, Lectures on Diseases of the Nerious Systcm, pp. 290-29u, note.

† The hyperzesthetic zones on the side of the thorax and the back appear to me to be correlated, and to have a relationship with hysterical inframammary pain. The following observation tends to support this view. In the case of a young lady suffering from inframammary pain, I was able to discover, by electro-diagnosis, that the intercostal nerve was much more sensitive than its neighbour, and that there was decided tenderness in the corresponding spinal region. In slight cases, this hyperæsthesia of back and side may not be much, if at all, affected by pressure; it is otherwise in cases of hysteria majơ. 
can be eliminated is a thing which may be demonstrated without much difficulty.

a. Unexpected Pressure may causc the Paroxy'sm.-An instance of this occurred during my visit to the hospital, when neither patient, nor physician, nor bystanders had reason to anticipate the event. - Having concluded his lecture (November I 1 th), in which, by the way, he discussed subjects other than paroxysms, and only referred to them incidentally, Professor Charcot withdrew from the hall. The four or five patients who had been present for reference retired likewise, and a number of the auditors chose to depart by the same corridor. Physicians as well as students from different countries had assisted at the lecture, and one of these (suspected to be a Wallachian) rudely rubbed with his hand the sensitive zone known to exist on the back of the patient preceding him. Immediately, a cry was heard, and the patient was seen to have fallen on the tiled floor in violent convulsions. A most severe paroxysm ensued. The culprit escaped in the confusion, and the incident naturally gave rise to much annoyance and indignation; for the patient might have received grave injuries. However, the reckless scepticism of the offender supplies an indubitable proof of the effect of unexpected pressure.*

b. Unexpected Pressure may terminate the Paroxysm.-When the hystero-epileptic fit is going through its evolution, the application of strong pressure to the sensitive regions will arrest it in any stage of its course. The patient's mind at this time is incapable of exerting influence; for, when the act is suddenly done, she awakes abruptly but incompletely, as from a dream-drama, with the incidents of which her thoughts are still concerned. When questioned as to what has happened, her muttered answers betray that her imagination is still vividly affected by things remote and alien to the place. It has been found that, if, instead of applying pressure, a strong continued current be sent through brain and body, the same effect of immediate awakening will be produced.

c. Expected Pressure may be quite ineffectual.-In most patients, there are intervals of greater or less duration between the paroxysmal periods or hysterical high tides, as Professor Charcot graphically calls them. Now, during this space, it is impossible to cause the production of the hystero-epileptic fit. The physician may be anxious that foreign visitors shall have the opportunity of witnessing the evolution of the paroxysm; the patient's attention may be vividly aroused by the proceedings, and a feeling of expectancy excited ; nevertheless, all ends in disappointment.

From the foregoing, it follows that psychical and physical agencies may produce identical results; next, that these hysterical phenomena may be caused- $\mathbf{I}$. By violent emotion without expectancy; 2. By emotion with expectancy ; 3. By purely physical means, quite distinct from, and independent of, emotion, whether with or without expectancy. It is a self-evident consequence of this that a demonstration of the efficiency of any one of these factors in a given case does not exclude the potential efficiency of the others. If it were shown that, in a certain patient, the phenomena could be produced by expectant attention, the experiments at $\mathrm{La}$ Salpêtrière would neither be disproved nor invalidated.

3. The Crisogenic Region.-It is not essential that the hysterica diathesis should be present, in order that a convulsive fit shall be determined by pressure on particular peripheral regions which I may be permitted to designate by the generic term "crisogenic". A case in point came under my observation five years ago in the Hôtel Dieu, in the wards of Professor Ball, then acting for my late master Professor Béhier. The patient had been a cavalry soldier, and, falling from his horse, he had received some severe injuries in the back and head, after which he became subject to epileptiform fits. Dr. Duchenne (de Boulogne) was invited to examine the case, and, recalling a noted physiological experiment, he proceeded to ascertain whether there might not be a zone épileptogène discoverable. He succeeded; for, on investigation, it was found that pressure applied over the dorsal vertebræ was immediately followed by an epileptiform fit. Hysteria there was none, neither could there have been any expectancy, as the patient was given no reason to anticipate anything other than a careful examination. This experiment, which took place in the presence of Dr. Lionville, chef du laboratoire, myself, and Professor Ball, was made the subject of a clinical lecture by the latter. If the influence of a psychical cause in determining the crisis here should still seem probable to any reader, then it should be added that the experiment in question was suggested by the discovery of Professor Brown-Séquard that epileptogenic zones are to be found in animals after spinal injury.

$\ddagger$ Dr. Wilks (British MEdical Journal, January I8th), mentions cases where local and general hysterical symptoms were the consequences of injuries received by
the patient.
Mental action can scarcely cause much interference where the guineapig is concerned. However, lest some partisan of animal intelligence should still suspect the existence of a possible cause of error, it may be mentioned that similar epileptiform fits can be produced (respiration being kept up artificially) even after removal of the brain. This eliminates expectant attention.

\section{[To be continued.]}

\section{TW O CASE O F H Y TER I A.}

By JOHN S. BRISTOWE, M.D., F.R.C.P., Senior Physician and Lecturer on Medicine at St. Thomas's Hospital.

CASE I. Hysteria: Paraplegia: Convulsions: Analgesia: Asthma, etc. -M. N., a florid healthy-looking girl, aged 18, was admitted into St. Thomas's Hospital, under my care, on April 18th, 1876. Her mother died at the age of 45 of consumption. Her father, who was rheumatic, was alive at the age of 63 . She has had nine brothers and sisters, of whom eight are living and well; the ninth died of pyæmia after an operation. She said that she had always been weakly and nervous; that she was liable to take cold; and that, about twelve months ago, she began to experience some difficulty in walking, which increased upon her gradually, so that, in October last, she had lost all power of locomotion, and had continued thus ever since. She had been liable also to attacks of severe trembling, especially of the arms.

On admission, she was found to have completely lost the use of her lower extremities, so that she was unable to move them at any joint, or to move even her feet or toes. She complained of a feeling of "pins and needles" in her feet; but ordinary tactile sensibility was present everywhere. The limbs could be readily moved for her, but were not limp. No reflex phenomena could be induced by tickling the soles of the feet; and faradism, which was applied without causing any pain, had much less effect than was natural in producing contraction of the muscles. There was no wasting. She had perfect control over the rectum and bladder. The heart, lungs, and kidneys were quite healthy. The pulse was regular and natural. Temperature was normal. The tongue was clean; the appetite poor. There was no affection of the bones of the spine; but she complained of pain in the small of the back, shooting occasionally into the groins and down the legs.

There was no change in her symptoms during the next ten days; but, on the morning of the 28th, about eight or nine o'clock, while sitting in a chair, she was attacked with convulsive movements of a choreic character, mainly implicating the left side of the body. An hour or two later, these became general and so violent, that she was precipitated from her chair on to the floor. She was placed in a cold bath without benefit ; thence she was removed to bed, and one-third of a grain of hydrochlorate of morphia was injected subcutaneously. In bed, she became extremely violent; the convulsions were continuous, and she bruised her arms against the sides and back of the bed, and kicked the skin off her heels. The morphia having had no effect, chloroform was administered, and shewwas kept under its infuence from 12.30 to I. 30 P.M.; but, when its, use was then intermitted, she became as violent as ever. The chloroform was repeated, however, and continued until 2.45. At this time, forty grains of chloral were given; but she was more violent after it than before. The dose was repeated at five and again at six, after which she went to sleep, and continued asleep until 4.30 the next morning. On waking, she became noisy and violent, with constant jactitation. At 9.30, the wet pack was employed with some advantage. During the day, she had frequent paroxysms at intervals sometimes of an hour. In those she was convulsed, violent, foamed at the mouth (without biting the tongue), barked incessantly like a dog, and frequently called out " take the beast away". She was very violent during the following night, requiring more than one nurse to take care of her; and the chloral had to be repeated.

On the morning of the $30 t h$, she was conscious; but her voice was hoarse; her pulse 100; her tongue coated; and her temperature $98.9 \mathrm{deg}$. She had during the day several convulsive attacks, one of which lasted three-quarters of an hour. They were less violent, however, than those of the previous day, and were attended with barking and whining. In the evening, one-third of a grain of morphia was injected subcutaneously.

It must be observed that, during the convulsive attacks, she moved her legs as freely as her arms; and that, throughout the three days, she took beef-tea and milk with little difficulty.

After the subsidence of this attack, her condition was identical with that on admission. She seemed fairly well; took her food without much trouble; but had no power whatever over the legs; and now and then would be attacked with tremulous or convulsive movements. These 